\title{
A Histopathological Study of Skin Lesions in Individuals with Oculocutaneous Albinism in Togo in 2019
}

\author{
Bayaki Saka (D), ${ }^{1}$ Julienne Noude Teclessou $\left(D,{ }^{2}\right.$ Sefako Abla Akakpo $\left(D,{ }^{1}\right.$ Piham Gnossike, ${ }^{3}$ \\ Kwamé Doh, ${ }^{4}$ Saliou Adam, ${ }^{5}$ Abas Mouhari-Toure, ${ }^{6}$ Garba Mahamadou, ${ }^{1}$ \\ Panawé Kassang, ${ }^{1}$ Yvette Elegbede Moise, ${ }^{7}$ Tchin Darre $\mathbb{D}^{8}{ }^{8}$ Koussake Kombate, ${ }^{2}$ \\ and Palokinam Pitché ${ }^{1}$
}

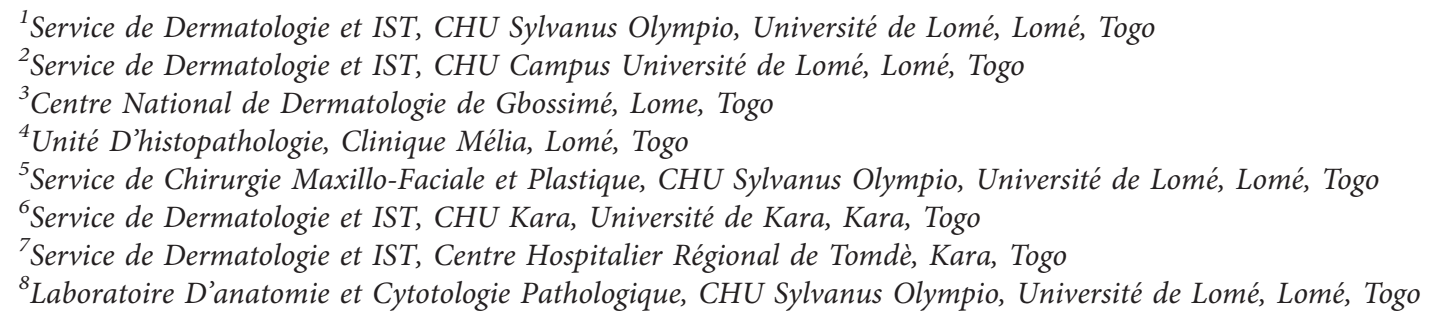

Correspondence should be addressed to Julienne Noude Teclessou; tjulie06@yahoo.fr

Received 6 May 2020; Accepted 9 July 2020; Published 29 July 2020

Academic Editor: Silvia Moretti

Copyright (C) 2020 Bayaki Saka et al. This is an open access article distributed under the Creative Commons Attribution License, which permits unrestricted use, distribution, and reproduction in any medium, provided the original work is properly cited.

Objective. The aim of this study was to study the histopathological patterns of skin lesions in persons with albinism (PWA) in Togo in 2019. Method. During two mobile skin care clinics in 2019, biopsies/excisional biopsies were performed in PWA in case of clinical doubt or in front of lesions suspected to be cancerous for histological examination. Anatomopathological reports were thus analysed. Results. During the two mobile skin care clinics, 115 biopsies/excisional biopsies were carried out in 79 PWA, with a mean age of $24 \pm 16.1$ years. Histological examination led to a diagnosis in 110 cases $(95.6 \%)$ and was inconclusive in 5 cases (4 cases of uncertain histological diagnosis and one case of nonspecific histological lesions). Fourteen different histological diagnoses were made, with a frequency ranging from $0.9 \%$ (one case) to $26.9 \%$ (31 cases). The four most frequent diagnoses in descending order were basal cell carcinomas (BCCs) (31 cases; 26.9\%), invasive squamous cell carcinomas (SCCs) or Bowen's disease (23 cases; $20 \%$ ), keratosis (20 cases; $17.3 \%$ ), and cysts (seven cases; $6.1 \%$ ). The 54 skin carcinomas were diagnosed in 33 (41.8\%) of the 79 patients who underwent skin biopsies/excisional biopsies. The BCC/SCC ratio was 1.3. No cases of cutaneous melanoma had been diagnosed. Conclusion. Skin cancers represent the main histological diagnosis in PWA (46.9\%) in Togo in 2019. The pattern of cutaneous malignancies in PWA shows the same trend as that seen in Caucasians with a predominance of basal cell carcinomas.

\section{Introduction}

Oculocutaneous albinism is an inherited disease characterized by the total or partial absence of melanin in the skin, hair, and eyes $[1,2]$. Melanin, the pigment responsible for skin colour, is photoprotective against carcinogenic ultraviolet radiation [3]. Its deficiency in people with albinism (PWA) predisposes them to the harmful effects of this radiation, with the development of actinic damage and a major risk of skin cancer [4-6]. The diagnosis of skin diseases in PWA very often requires histological examination [2, 7-9], especially in the case of skin lesions suspected of being cancerous. Indeed, the fear of the practitioner is the early detection of these skin cancers in this population because of their very high frequency, varying from 23 to $26 \%$ depending on the series [9-12]. We conducted this study in order to study the histopathological patterns of skin lesions in persons with albinism (PWA) in Togo in 2019. 


\section{Method}

Two rounds of free mobile skin care clinics took place throughout the Togolese territory in 2019 in order to treat malignant and premalignant lesions in PWA. These campaigns covered 10 cities in Togo, the first in June and July 2019 and the second in October and November 2019. Dermatological consultations were provided by a senior dermatologist. Biopsies/excisional biopsies were carried out in case of clinical doubt or in front of lesions suspected of being malignant and sent to the laboratory of pathology of the Sylvanus Olympio University Hospital or to the histopathology unit of the Mélia clinic in Lomé for histological examination. Two pathologists assisted in carrying out the histological examinations. Anatomopathological reports were collected and analysed. The data collected were sociodemographic (age and sex) and histological diagnosis.

\section{Results}

During these two campaigns, 115 biopsies/excisional biopsies were carried out for histological examination in 79 patients, with an average of 1.5 biopsies/excisional biopsies per PWA. Indeed, 24 of the 79 patients had more than one biopsy/excisional biopsy (15 had two biopsies/excisional biopsies, 6 had three biopsies/excisional biopsies, and 3 had four biopsies/excisional biopsies). The mean age of the 79 patients was $24 \pm 16.1$ years (extremes: 7 and 75 years), and the sex-ratio $(\mathrm{M} / \mathrm{F})$ was 1 . All of these 115 biopsies were cutaneous.

Histological examination led to a diagnosis in 110 cases (95.6\%) and was inconclusive in 5 cases, including 4 cases of uncertain histological diagnosis and 1 case of nonspecific histological lesions.

Fourteen different histological diagnoses were made, with a frequency ranging from $0.9 \%$ (one case) to $26.9 \%$ (31 cases). The four most frequent diagnoses in descending order were basal cell carcinomas (BCCs) (31 cases; 26.9\%), invasive squamous cell carcinomas (SCCs) or Bowen's disease (23 cases; $20 \%$ ), keratosis (20 cases; $17.3 \%$ ), and cysts (seven cases; 6.1\%) (Table 1). The 54 cutaneous carcinomas were diagnosed in $33(41.8 \%)$ of the 79 patients who underwent skin biopsies/excisional biopsies. The BCC/SCC ratio was 1.3. No cases of cutaneous melanoma had been diagnosed.

\section{Discussion}

In our study, 115 biopsies/excisional biopsies were performed in 79 PWA, an average of 1.5 biopsies/excisional biopsies per PWA. This rate is comparable to that found (1.6 biopsies per PWA) in Tanzania where 134 biopsies were performed on 86 PWA [2]. In Nigeria [9], 58 biopsies were taken from $30 \mathrm{PWA}$, corresponding to 1.9 PWA biopsies. These results show that suspicious skin lesions requiring skin biopsy are most often multiple in the same PWA, probably due to the effects of ultraviolet radiation. Moreover, the main reason for biopsies/excisional biopsies in PWA is especially when skin lesions are suspected to be malignant, as the practitioner's obsession is the early detection of these skin cancers in this population because of their very high frequency [9-12]. In the series of Enechukwu et al. [9], skin biopsy was performed on suspicion of premalignant or malignant lesions in 38\% and 32\% of cases, respectively.

Histological examination resulted in a histological diagnosis of certainty in 110 (95.6\%) of the 115 biopsies/excisional biopsies in our study. In a French study on penile dermatosis in the general population [13], this histological examination led to a diagnosis in $85.5 \%$ of cases. Rajaratnam et al. [14] in Ireland found in the study of general population that, in $55 \%$ of cases of inflammatory dermatosis, histology led to a diagnosis of certainty, even without any clinical information provided to the pathologist. These results show the value of histology in dermatology for the diagnosis of skin diseases.

In our study, $33(41.8 \%)$ of the 79 patients who had undergone biopsies/excisional biopsies had skin carcinomas (BCCs in $26.9 \%$ of cases and invasive or in situ SCC in $20 \%$ of cases). Other histological diagnoses were dominated by keratosis $(17.3 \%)$, cysts $(6.1 \%)$, hamartoma $(6.2 \%)$, nodular folliculitis $(6.1 \%)$, and benign squamous papillomas (6.1\%). In the series of Enechukwu et al. [9], 18 (60\%) of the 30 patients biopsied had skin carcinomas including BCC (37.9\%), SCC (15\%), basosquamous carcinoma (12\%), and collision tumour (BCC and SCC, 3.4\%). Other histological diagnoses were actinic keratosis (15\%), nevi (12\%), solar elastosis (1.2\%), and psoriasis (1.7\%). From these two studies, premalignant and malignant dermatosis were found to be the main histological diagnosis in PWA (46.9\% in our series versus $83.3 \%$ in the Nigerian series [9]). These results confirm the impact of the sun, with a high prevalence of actinic damage and skin cancer. Indeed, the appearance of actinic lesions in PWA is not only related to age $[4,10]$ but also and especially to the hot and sunny climate $[15,16]$.

In our study, there was a predominance of BCC with a $\mathrm{BCC} / \mathrm{SCC}$ ratio of 1.3 . This predominance could be explained by the fact that, in our case, it is the dermatologist who goes to the PWA, which allows us to detect mild cases. In Nigeria [9], BCC was also the most frequent skin carcinoma (55\%), followed by SCC (22\%), basosquamous carcinoma (12\%), and collision tumour (BCC and SCC, $3.4 \%$ ). In Brazil [10], $62 \%$ were BCC, $51 \%$ were SCC, and $7 \%$ were melanoma. All three studies, including ours, were population-based studies. However, most of the African studies, all hospital series, show that SCC is the most common cancer in this population [2, 17-19]. Finally, melanoma is rare in PWA with a similar incidence in the general population [10], a tumour that was not by us and Enechukwu et al. [9].

Limitations of study: the main limitation of this study is that histological examinations were performed by general pathologists and not dermatopathologists. Nevertheless, in 95.6\% of cases, the histological examination made a diagnosis. 
TABLe 1: Histological diagnosis in PWA in Togo in 2019.

\begin{tabular}{lcc}
\hline Histological diagnostics & Number & \\
\hline Basal cell carcinomas & 31 & 23 \\
Squamous cell carcinomas (in situ and invasive) & 23 & 20 \\
Keratosis* & 7 & 20.0 \\
Cysts (epidermal, synovial, and sebaceous) & 6 & 17.3 \\
Hamartomes (folliculo-sebaceous, verruca sebaceous, and angiocrine) & 6 & 6.1 \\
Nodular folliculitis & 6.2 \\
Benign squamous papillomas & 4 & 5.2 \\
Hyperplastic fleshy buds & 2 & 5.2 \\
Lipomes & 1 & 3.5 \\
Plantar wart & 1.7 \\
Psoriasis & 1 & 0.9 \\
Supposedly benign round cell tumour & 1 & 0.9 \\
Ulcerated benign lobular hemangioma & 1 & 0.9 \\
Boil & 1 & 0.9 \\
Nonspecific skin ulceration & 1 & 0.9 \\
Histological diagnosis uncertain & 4 & 115 \\
Total & 0.9 \\
\hline
\end{tabular}

*Actinic (2); benign (14); HPV/wart (4).

\section{Conclusion}

The results of this study show that skin cancers represent the main histological diagnosis in PWA (46.9\%) in Togo in 2019. The pattern of cutaneous malignancies in PWA shows the same trend as that seen in Caucasians with a predominance of basal cell carcinomas. The popularization and respect of photoprotection measures and systematic and regular examination of the skin of these PWA will allow early detection and management of these skin cancers.

\section{Abbreviations}

$\begin{array}{ll}\text { ANAT: } & \text { National association of albinos of Togo } \\ \text { BCC: } & \text { Basal cell carcinoma } \\ \text { NGO: } & \text { Nongovernmental organization } \\ \text { PWA: } & \text { Patients with albinism } \\ \text { SCC: } & \text { Squamous cell carcinoma } \\ \text { SOTODERM: } & \text { Togolese society of dermatology and sexually } \\ & \text { transmitted infections } \\ \text { UV: } & \text { Ultraviolet. }\end{array}$

\section{Data Availability}

Extracted data are with the authors and available for sharing on request.

\section{Ethical Approval}

This study was authorized and approved by the National Association of Albinos of Togo (ANAT), the Togolese Society of Dermatology and Sexually Transmitted Infections (SOTODERM), the Maxillofacial and Plastic Surgery Department, and the Ministry of Health of Togo.

\section{Consent}

The authors obtained oral consent from patients who participated in the study.

\section{Conflicts of Interest}

The authors declare that they have no conflicts of interest.

\section{Authors' Contributions}

BS, PP, and GM were responsible for the conception of the study, participated in the study design, undertook the field study, conducted the data collection, analysis, and interpretation, and wrote the manuscript. They have revised and finalized the manuscript. JNT, PK, SA, SAK, PG, and YEM were involved in the data collection, analysis, and interpretation. They wrote and finalized the manuscript. AMT, $\mathrm{TD}$, and KK were involved in data analysis and interpretation. All the authors were responsible for the overall scientific management of the study, for analysis and interpretation, and the preparation of the final manuscript. Finally, all the authors read and approved the final manuscript to be submitted for publication.

\section{Acknowledgments}

The authors would like to thank the Pierre Fabre Foundation for fully funding this dermatological consultation project for people with albinism (PWA) in Togo. The authors also thank the National Association of Albinos of Togo (ANAT) for coordinating the PWA mobile clinics in 2019.

\section{References}

[1] E. S. Hong, H. Zeeb, and M. H. Repacholi, "Albinism in Africa as a public health issue," BMC Public Health, vol. 6, p. 212, 2006.

[2] S. K. Kiprono, B. M. Chaula, and H. Beltraminelli, "Histological review of skin cancers in African albinos: a 10-year retrospective review," BMC Cancer, vol. 14, pp. 1471-2407, 2014.

[3] M. Sengupta, D. Sarkar, M. Mondal, S. Samanta, A. Sil, and K. Ray, "Analysis of MC1R variants in Indian oculocutaneous 
albinism patients: highlighting the risk of skin cancer among albinos," Journal of Genetics, vol. 92, no. 2, pp. 305-308, 2013.

[4] S. E. Emadi, A. Juma Suleh, F. Babamahmoodi et al., "Common malignant cutaneous conditions among albinos in Kenya," Medical Journal of the Islamic Republic Of Iran, vol. 31, no. 1, 2017.

[5] A. N. Okoro, "Albinism in Nigeria: a clinical and social study," British Journal of Dermatology, vol. 92, pp. 485-492, 1975.

[6] J. Luande, C. I. Henschke, and N. Mohammed, "The Tanzanian human albino skin: natural history," Cancer, vol. 55, no. 8, pp. 1823-1828, 1985.

[7] G. Van Der Westhuizen, C. A. Beukes, B. Green, W. Sinclair, J. Goedhals, and J. Goedhals, "A histopathological study of melanocytic and pigmented skin lesions in patients with albinism," Journal of Cutaneous Pathology, vol. 42, no. 11, pp. 840-846, 2015.

[8] M. I. Perez and J. L. Sanchez, "Histopathologic evaluation of melanocytic nevi in oculocutaneous albinism," The American Journal of Dermatopathology, vol. 7, pp. 23-28, 1985.

[9] N. A. Enechukwu, G. O. Ogun, O. I. Ezejiofor et al., "Histopathologic patterns of cutaneous malignancies in individuals with oculocutaneous albinism in anambra state, Nigeria: a paradigm swing?” Ecancer Medical Science, vol. 14, p. 1013, 2020.

[10] C. R. Marçon, J. C. Moraes, M. A. M. De Olivas Ferreira, and C. B. Oliari, "Dermatological and epidemiological profiles of patients with albinism in são paulo, Brazil, between 2010 and 2017: a cross-sectional study," Dermatology, vol. 236, no. 3, pp. 219-227, 2020.

[11] D. P. Lookingbill, G. L. Lookingbill, and B. Leppard, “Actinic damage and skin cancer in albinos in northern Tanzania: findings in 164 patients enrolled in an outreach skin care program," Journal of the American Academy of Dermatology, vol. 32, no. 4, pp. 653-658, 1995.

[12] J. G. Kromberg, D. Castle, E. M. Zwane, and T. Jenkins, "Albinism and skin cancer in southern Africa," Clinical Genetics, vol. 36, no. 1, pp. 43-52, 1989.

[13] J.-N. Dauendorffer, C. Renaud-Vilmer, M. Bagot, and B. Cavelier-Balloy, "Intérêt de la biopsie cutanée dans le diagnostic des dermatoses péniennes," Annales de Dermatologie et de Vénéréologie, vol. 139, no. 8-9, pp. 521-525, 2012.

[14] R. Rajaratnam, A. G. Smith, A. Biswas, and M. Stephens, "The value of skin biopsy in inflammatory dermatoses," The American Journal of Dermatopathology, vol. 31, no. 4, pp. 350-353, 2009.

[15] C. Y. Wright, M. Norval, and R. W. Hertle, "Oculocutaneous albinism in sub-saharan Africa: adverse sun-associated health effects and photoprotection," Photochemistry and Photobiology, vol. 91, no. 1, pp. 27-32, 2015.

[16] C. Y. Wright, D. J. Du Preez, D. A. Millar, and M. Norval, "The epidemiology of skin cancer and public health strategies for its prevention in southern africa," International Journal of Environmental Research and Public Health, vol. 17, no. 3, p. 1017, 2020.

[17] J. B. Mabula, P. L. Chalya, M. D. Mchembe et al., "Skin cancers among albinos at a university teaching hospital in northwestern Tanzania: a retrospective review of 64 cases," BMC Dermatology, vol. 12, no. 1, p. 5, 2012.

[18] O. Awe and T. Azeke, "Cutaneous cancers in Nigerian albinos: a review of 22 cases," Nigerian Journal of Surgery, vol. 24, no. 1, pp. 34-38, 2018.

[19] K. O. Opara and B. C. Jiburum, "Skin cancers in albinos in a teaching hospital in eastern Nigeria-presentation and challenges of care," World Journal of Surgical Oncology, vol. 8, no. 1, pp. 73-79, 2010. 